\title{
Educational pathways of Black women physicists: Stories of experiencing and overcoming obstacles in life
}

\author{
Katemari Rosa \\ Department of Physics, Federal University of Campina Grande, Avenida Aprigio Veloso, 882, Bloco CY2, \\ Campina Grande, Paraíba, 58429-9000, Brazil \\ Felicia Moore Mensah \\ Department of Mathematics, Science, and Technology, Teachers College, Columbia University, \\ 525 West 120th Street, Box 210s, New York, New York 10027, USA
}

(Received 24 January 2015; published 1 August 2016)

\begin{abstract}
[This paper is part of the Focused Collection on Gender in Physics.] This is an empirical study on the underrepresentation of people of color in scientific careers. Grounded in critical race theory, the paper examines the lived experiences of six Black women physicists and addresses obstacles faced in their career paths and strategies used to overcome these obstacles. Data for this study were collected through semistructured interviews and coded for emergent themes. The findings reveal that college recruitment and funding were fundamental for these women to choose physics over other STEM fields. In addition, Black women experience unique challenges of socialization in STEM, particularly by exclusion of study groups. We suggest physics departments provide a more inclusive environment to support Black women in science.
\end{abstract}

DOI: 10.1103/PhysRevPhysEducRes.12.020113

\section{INTRODUCTION}

[...] being poor, of Color, and also a woman results in daily experiences that create a systematically different relationship to knowledge [including its production, comprehension, and integration] [1].

We live in a connected world where a variety of information, practices, and values can be accessed from across the United States and worldwide. However, in spite of the globalization phenomenon, women of African descent have distinct cultural experiences according to their ethnic origins. These experiences intrinsically shape their understanding of the world, and therefore constitute elements that influence their images of science and scientists. Consequently, these women relate to science in distinct ways. The investigations on underrepresented groups in science have received significant attention [2-4]; however, there is still a gap in the literature related to the success and experiences of Black women in physics. Thus, it is necessary to understand how Black women physicists choose and then pursue careers in the sciences. In addition, the understanding of the life experiences of women of color in physics in the United States can provide valuable insights for studies of people of color in the

Published by the American Physical Society under the terms of the Creative Commons Attribution 3.0 License. Further distribution of this work must maintain attribution to the author(s) and the published article's title, journal citation, and DOI. sciences in other countries [5]. This study is targeted to physics education researcher, and those in the scientific community in general, who are who are particularly interested in learning about the experiences and fostering the presence of Black women in science.

The number of Black people (men and women) receiving bachelor degrees in science, technology, engineering, and mathematics (STEM) fields has increased by $34 \%$ between 1995 and 2004 [2], which shows progress. However, the underrepresentation of this racial and ethnic group remains high. In 2004, while Black people were $12 \%$ of the overall population in the United States [6], they represented only $7 \%$ of the bachelor degree recipients in science and engineering fields in that year. The situation worsens as the degree level increases. In the same year, Black people were responsible for 3.3\% of all masters' and $1.9 \%$ of all doctoral degrees awarded in science and engineering [2]. As an expected consequence of the low level of doctoral degree production, there are very few people of African descent occupying faculty positions [7]. Of all full-time faculty at four-year institutions in engineering, only $4.9 \%$ were of Black people in fall 2003, and in the same period only $3.4 \%$ of all full-time faculty at four-year institutions in the natural sciences were of African descent [2]. Almost ten years later, the situation was not much different. Landivar [8] shows that Black people were only $7 \%$ of the bachelor degree recipients in STEM in 2011.

If we approach the underrepresentation of Black women in STEM only in terms of gender, we find the gap persists. Black women were $11 \%$ of all women receiving bachelor degrees in 2010, but only $2.9 \%$ of women receiving physics bachelor degrees in the same year [9]. Furthermore, White 
women received $73.5 \%$ of physics bachelor degrees awarded to women in 2010 [9]. There are 25 times more White women than Black women in physics, but only 6 times more in total have bachelor degrees. These data show there is an intersection of race and gender when it comes to underrepresentation of people in science.

The only scientific field where African American women (and women in general) are overrepresented is the biological sciences; Black women were awarded $72 \%$ of bachelor's degrees received by Black people in biological sciences in that same year [2]. These numbers provide a panoramic view of the insertion of Black people in scientific careers in the United States, but they cannot give information about what happens at the individual level.

For an account of the struggles, perceptions, and experiences of Black people pursuing scientific careers it is necessary to check the qualitative research produced in this area. We classify that research into two types according to their approach. First, there are investigations that concentrate on the reasons of failure of people of color in the sciences [10-13]. Second, there are works that focus on successful cases seeking to understand their histories [14-16]. This study focuses on the positive perspective. Even though we recognize the relevance of revealing and understanding the reasons that exclude Black people from the sciences, we believe it is also important to look at the experiences of those who have overcome the challenges in pursuit of STEM careers. In this direction, the literature indicates that at the individual level strong precollege science experiences, family support, teacher encouragement, intrinsic motivation, and perseverance serve as critical factors for the success of people of color in scientific programs [17-19]. Adding to that body of work, this study focuses on successful cases of Black women in physics. We examine the lived experiences of six Black women physicists. Looking at their educational trajectories, we aim to answer the following questions: what are the obstacles they identify along their career paths, and what are the strategies they use to overcome these obstacles?

\section{THEORETICAL FRAMEWORK}

\section{A. Critical race theory}

In this section, we present critical race theory (CRT) as our theoretical framework and introduce three of its key elements, the permanence of racism, counterstorytelling, and interest convergence. Then we discuss CRT connections with education and science education. We do not intend to provide an extensive discussion on the fundamentals of CRT, but to show components from this theory that help us make sense of the data in terms of race relations in the United States.

Critical race theory is a movement that started in the 1970s. It was formed primarily by scholars of color and born out of the legal scholarship [20]. According to
Delgado [21], CRT's starting point can be traced to the early work of Derrick Bell and Alan Freeman, "both of whom were deeply distressed over the slow pace of racial reform in the United States" (p. xiii). At that time, they argued that many of the gains of the civil rights movement of the 1960s had been diminished, and that traditional approaches such as marching and protesting were less effective than they used to be [21]. They were soon followed by other legal scholars who were concerned with racial inequalities in the United States.

CRT has evolved over time and we cannot say there is a common doctrine to which all CRT scholars subscribe, but there are several defining elements that makeup this intellectual movement $[20,22]$. For the purposes of this study, however, we explore only three of these key elements: the centrality of race and racism, interest convergence, and counterstorytelling.

The permanence of racism. - A basic insight underlying CRT is that "racism is normal, not aberrant, in American society" [21] (p. xiv). Delgado [21] explains that "racism is an ingrained feature of our landscape, it looks ordinary and natural to persons in the culture" (p. xiv), and argues that equal opportunity programs can remedy cases of blatant injustice but have little effect on the usual racism people of color encounter every day. In other words, CRT understands racism as a structural component of society in the United States. Racism here is understood as a system of advantage and disadvantage based on race [23]. This system perpetuates advantages and privileges for white people, and disadvantages for people of color. Unlike prejudice, which relates to preconceived notions and judgments made by individuals, racism does not rely on one person but a set of "cultural messages and institutional policies and practices as well as the beliefs and actions of individuals" [23] (p. 7). The benefit of receiving these advantages, even if not called for or even without any prejudice involved, is understood as white privilege.

Counterstorytelling.-Another premise shared by CRT theorists stands for the centrality of experiential knowledge and the importance of telling the stories of people of color. These lived experiences are told using "methods as storytelling, family histories, biographies, scenarios, parables, cuentos, testimonios, chronicles, and narratives" [24] (p. 26). By telling stories of people who usually do not have their voices heard, CRT writers aim to challenge racial oppression. These stories are called counterstories because they are used to analyze and confront stories of those in power [24].

Interest convergence.-Two of Bell's essays that paved the beginning of CRT, "Serving two masters" and "Brown v. Board of Education and the interest convergence dilemma," discuss how school integration happened not because it would be of the best interest for the education in the Black community, but because it fitted interests of White people [20]. Bell [25] argues black People had been 
fighting for desegregated public schools since 1850, but it was only when "racial segregation was hampering the United States in the Cold War with communist nations and undermining U.S. efforts to combat subversion at home" (p. 1056) that White legislators decided that ending segregation was the right thing to do. Interest convergence holds that "White elites will tolerate or encourage racial advances for Blacks only when they also promote White self-interest" [21] (p. xiv). Therefore, actions and policies that benefit the Black population are only obtained when also benefiting White people.

\section{CRT and education}

CRT has crossed frontiers and has been present in the field of education since the 1990s, when it was first introduced by Gloria Ladson-Billings and William Tate [26]. Grounded on CRT perspectives, Ladson-Billings [27] discusses how education constructed diversity, showing that in the 1960s educators examined what was called "culturally deprived or disadvantaged" children; these children were essentially not White and middle class. In the 1980s, there was the discourse of teaching students "at-risk," mostly because of the report A Nation at Risk that was released in 1983 by the Commission on Excellence in Education. The report stated that the entire nation was in risk on several aspects, including education. The label "at-risk" ended up not identifying the entire nation but only a group of children, and it "became synonymous with being a person of color" [27] (p. 218). Ladson-Billings [27] argues teachers refer to diverse or multicultural settings when they actually want to refer to people of predominantly African descent or Latino schools; the "construction of difference" is a central discursive practice for justifying our need to "prepare teachers for student diversity" (p. 216). CRT in education provides a new perspective to look at racial issues continuously present in schooling.

In science education, critical race theory is still incipient [28]. Butler [29] talks about Black scientists who succeeded during the Jim Crow period in the United States, and provides several classroom activities, materials, and strategies in science education, employing CRT not only for basic research but also to develop instructional materials. In the most recent Handbook of Research on Science Education, Parsons [28] explicitly recommends using CRT in the study of race and ethnicity in this field. Furthermore, Mensah and Jackson [30] used CRT in science teacher education, telling stories of elementary preservice teachers' experiences. Thus, we believe critical race theory can emerge as a potent theoretical framework to discuss race and ethnicity in physics education, and particularly with Black women physicists. Therefore, the articulation of critical race theory provides us the grounding to interpret the lived experiences of Black women physicists in this study. It is through this lens we frame the following questions: what do Black women physicists identify as obstacles in their career paths and what strategies do they use to overcome these obstacles?

In the sections that follow, we present the methods used to collect and analyze the data, followed by the findings with a characterization of the participants of the study. Next, there is the discussion of the findings, or the themes that emerged in the investigation. Last, we present implications and conclusions, and finally ideas for further research on this topic.

\section{METHODS}

\section{A. Data collection}

In order to identify Black women physicists in the United States, we made available an online survey to gather initial information on possible participants. We distributed the survey link among members of professional associations such as the National Society of Black Physicists (NSBP) and the American Physical Society, as well as social networks, such as LinkedIn, Google Plus, and Facebook. In addition, we sent the survey link directly to the scientists that were in the NSBP Black Women Physicist database (which includes not only their members). The purpose of this initial survey was to gather general information about our available population, and to use this data to select the participants for follow-up in-depth interviews. The survey covered, for example, questions about academic background, ethnic affiliation, and current work status. In addition to the survey, we recruited participants during a NSBP conference.

In the second stage of the data collection, we selected the participants for in-depth interviews using the following criteria: they held a Ph.D. degree in physics, astronomy, or related field (assessed on an individual basis); selfidentified as Black or African American; and indicated willingness to participate in in-depth interviews. In addition, the selection of the participants was restricted to those who had most of their education in the United States [31]. We sent an invitation to join the study to eleven women who answered they would agree to participate in interviews. It is worth mentioning the African American women in physics database (since 1972) lists a total of 83 African American women with Ph.D.'s in Physics, Astronomy, Astrophysics, Applied Physics, and Space Physics, including those that have been deceased [32]; therefore, we can assume a total population no larger than 90 in 2015 . Although eleven scientists agreed to participate in the interview phase of the study, we interviewed only five of them. For various reasons, such as schedule conflict, we did not interview the remaining six women. In the end, the sample consisted of six women-five recruited from the initial survey and one on the NSBP meeting site. These six women represented a small, focused sample of Black women in physics careers, working in diverse settings (i.e., the government sector, and half from colleges or 
universities). The sample makeup was similar to the pool from the initial survey, where these sectors made up $46 \%$ each of the pool. The participants' varied in age (number of years) from late twenties to mid fifties. We gave pseudonyms to the participants to offer some anonymity.

The primary data for the study was collected through interviews. The interviews were audio recorded in person at various locations across the United States, and ranged from 2 to 3 hours for each participant. One participant, Christa, had two interviews. Her second interview was ten months after the first encounter, and it was audio recorded via telephone and lasted about 40 minutes. Two other participants, Allyson and Shanna, were contacted after the interview through email for clarification on their stories. The other interviews did not require further clarifications. The same interview protocol, which consisted of 55 openended questions, was used for all six participants; however, refinements for the questions were made as the interview process continued, building upon the information that was collected in previous interviews.

\section{B. Data analysis}

We coded the interviews and analyzed the data to allow for emergent themes. The coding scheme that we used derived mainly from the data as in vivo coding. We did that by using the participants' own words and language to generate a code. For example, we generated the code "summer program" from the transcripts once we noticed this expression appeared repeatedly in the experiences of the women participating in this study. Additionally, there were codes that we derived from the theoretical framework. For instance, the code "family support" derived from the literature indicating one of the factors that influence the number of underrepresented groups in scientific careers.

We assigned a chunk of text to a particular code. Initially we created a code that related to the theme of the text. Then as other parts of the transcripts showed a connection with that theme, we coded the subsequent text and compared the texts to check for consistency on what could represent that theme. As an example, here we code the first time Christa talks about a summer program:

\section{[...] the physics teacher got this information about a summer program called [Program] at NASA[...] that was for minorities in science, and she said I was the only minority she knew and she didn't know if I was interested, but since I was the only one, she just gave it to me. (Christa)}

Then, in the following transcript, she does not use summer program but she makes reference to how she spent her summers in science related programs, which we now code as summer program: "And that was the summers of my junior and senior years of high school, and then the summer after my first year of college" (Christa). We expanded the code "summer program" to incorporate the mention REU (Research Experiences for Undergraduates), which she specifically mentioned in the transcript. This process was continued for all the codes that were assigned to chunks of text.

When analyzing a transcript of another participant, the same code was applied for texts that presented the same theme. In search of coherence between the quotes that were assigned under the same code, we compared the texts from different participants. For example, we cited an instance still using the summer program, which was developed into a code that refers to academic or research experiences related to science undertaken during the summer, as a special program in which the participants were funded to develop STEM research expertise, content knowledge, or practices.

Next, we combined codes that were related conceptually to each other but did not refer to the same types of events, thus creating categories. We used a multistep approach to produce a larger category. For example, the combination of "summer program", "scholarships and funding", "math performance", and "choice of major" led to the category "conditions to choose physics as a career." The personal narratives of the physicists were used in search of emergent themes (i.e., common trends among the transcriptions).

Using critical race theory as a guide through the analysis process, stories were selected based on the data collected in order to explore the emergent themes and to talk about them through a CRT framework. The stories were developed inductively, based on the data, and the analysis was made checking the counterstories against the dominant narrative available through the literature.

\section{Validity, rigor, and limitations}

For the coding process, we used the qualitative content analysis software ATLAS.TI, where each interview transcript was organized as a primary document (P-Doc). This allowed us to effectively compare quotes from different transcripts through constant comparisons. This process "assists the researcher in guarding against bias, for he or she is then challenging concepts with fresh data" [33]. Other elements of rigor used were peer debriefing [34] with a group whose shared expertise was in critical race theory. Group discussions helped us by identifying biases, underlying themes, and shaping up the stories.

Finally, we mention a few limitations of this study. Given the qualitative nature of the study and the storytelling methodology, the number of participants is relatively small. In addition, the positionality of the researchers influences the data collection and our analysis of the data [35]; still, as women of color in STEM, our analysis provides some experiential knowledge on the topic. Another limitation of the study relies on the limited relationship (or lack of) with the participants, which interferes with the quality (depth and extension) of the interviews. We tried to minimize these 
limitations with procedures such as peer debriefing, member checking, and in-depth interviews, as described above.

\section{FINDINGS}

This section presents short stories from the life of each physicists in the study. The stories serve to introduce the six Black women physicists by highlighting their current position, and then going backward to include stories of their upbringing and educational experiences. Following these individual case stories, we discuss obstacles the physicists face during their trajectory, and how they overcome these obstacles.

\section{A. Black women physicists' profiles}

Allyson.-Allyson holds a bachelor's degree in physics and a Ph.D. in material science and engineering. Allyson is a first generation Ph.D. degree holder of a middle class family from the southeastern U.S. Her parents raised their two daughters to develop very strong mathematical and science skills. Her father was an electrical engineer. Growing up in the suburbs, Allyson faced early on the differences between people of color and Whites in her neighborhood. In her school, there was a disparity in the number of students of color in the accelerated classes, and even in the treatment she received from some of her teachers. Teachers would challenge her presence in Advanced Placement (AP) classes and not offer her the same support they would for the White students.

Allyson grew up very involved in several extracurricular activities such as the Girl Scouts, the Step Team (dance), ballet, and the marching band. In addition, Allyson had the opportunity to participate in initiatives that fostered mathematics and science skills and targeted students of color. She attended summer programs and got tutoring in mathematics, biology, chemistry, and physics through these initiatives.

Allyson followed the steps of two of her cousins who were pursuing bachelor's degrees in the sciences at the same Historically Black College and University (HBCU) where Allyson did her studies. At this institution, the students were of color but the faculty was not, and she found that curious. Nevertheless, Allyson felt a great support from her academic community. However, when moving to the doctoral level, Allyson felt a great difference from the supportive HBCU environment to the hostile Predominantly White Institution (PWI). She did not see many people of color, unless they were working as janitors or on the custodian staff. Even though Allyson had a good relationship with her advisor, who was friend of her college advisor, she had some hard times with her male colleagues. They could not understand why she was there and not at home taking care of children and a husband, like their wives. Allyson got married during her doctoral studies, and although her husband is very supportive of her work, she recognized that it was a challenge to juggle graduate school and marriage. Over time, the relationship with her graduate colleagues evolved, but Allyson had challenges with them until they achieved peace. Allyson is in her first job, working for the government, and plans to have children in the future. As a researcher, she works on developing science and technology for the United States government.

Betty.-Betty holds a bachelor's degree in electrical engineering, and a masters and Ph.D. in physics. Betty grew up in a large urban environment in the midwest of the U.S. Her parents were greatly involved in activist circles, which provided Betty an environment to engage in social justice and Black movements that were strongly present in her upbringing.

None of her close relatives was in a scientific field. What brought Betty into the sciences was really her love for mathematics. She liked multiplication tables and figuring out the patterns of relationships between numbers. She always studied in public schools and participated in many after-school programs. Betty attended a top-rate quality magnet high school in which she focused her studies on science and mathematics and took as many honors and AP classes she could.

After participating in a few programs that aimed to recruit minority students for STEM disciplines, Betty enrolled in engineering school because she was already familiar with what she thought the profession was, and familiar with the institution she selected. College years were demanding, but not particularly challenging. During graduate school at a HBCU, Betty did not have much guidance from her advisors, but was given a lot of responsibilities and autonomy to build a lab and run it. She had a rare opportunity as a Ph.D. student to manage a laboratory in every single aspect of it - to teach people to work in the lab and give reports to the lab sponsors. Later, Betty shifted her career with a postdoctoral fellowship doing physics education research, followed by developing work in policies for STEM education.

Betty married later in life. Now at this point in her career, it is challenging to find mentors because few people do the type of work that she does, which requires a certain level of interdisciplinary expertise. Currently, she is a Research Analyst doing largely qualitative analysis and getting involved in issues of either conceptualization or quality control for both qualitative and quantitative projects.

Christa. - Christa holds a bachelor's and a Ph.D. degree in physics. Christa was the daughter of a long-distance driver who was mostly away during her childhood, so her mother, a very creative woman, would do everything possible to enable her children's dreams. Christa's mother mostly raised her and her two brothers.

Christa was an introverted child that did not have friends at school. She did not have a particularly stimulating 
science experience at school, and although her science teacher once wrote on her report card "she is not socially engaged and probably won't amount to anything," she always excelled in mathematics. In spite of financial difficulties, Christa encountered several educational opportunities during her childhood, through summer programs related to science, or access to free science museums. The combination of high mathematics performances and summer program experiences led Christa to major in physics in college. During her undergraduate years, Christa developed a larger social network in both the physics department and the institutions where she did summer research programs.

As the first member of her family to go to college, and the first Black student in her physics department at her undergraduate institution, Christa had a lot of pressure to excel. This pressure, in combination with some faith struggles, contributed to a physiological turmoil towards the end of her degree and a consequent departure from academia. After teaching high school physics for a while, Christa returned to academia and completed her Ph.D. She wanted to learn more physics and return to teaching high school. She got married. Contrary to what she initially envisioned for her career, she became a faculty member in a physics department, and is currently running her own laboratory. Christa is an Assistant Professor of physics in the astronomy and physics department of a liberal arts college.

Esther.-Esther is the youngest daughter of five, a wife, a mother of four, and the grandmother of six children. Being the youngest child of five, three girls and two boys, she was separated from her siblings when she was two years old. At that time, Esther's mother passed away and the family decided that the grandparents would take care of the children, so the girls went under the care of her mother's parents, and her brothers stayed with her father's parents.

Esther was raised in a rural area, where her grandfather raised hogs and her grandmother worked as a cook. Her grandmother would bring leftover food home for the hogs. Esther's grandparents were very involved in her school; her grandfather was the president of the Parent-Teacher Association (PTA) and her grandmother, being the school's cook.

When growing up Esther played ball, cards, and board games. She said that her favorite toys growing up as a girl were dolls, highlighting the gendered character of her toys during childhood. She did not have chemistry sets or any other toys that people would consider science related. In fact, she cannot really relate her experiences at a young age with science. It was just later in school that she had contact with science classes. When Esther transitioned from a segregated to an integrated school, her grandmother made sure to remind her that she was a good student and she should not feel intimidated in the new school. In mathematics class, Esther could do the calculations and answer the problems, but she did not really know the relevancy. She became disinterested in science, until one of her teachers told her she was doing really great on her exams, while her colleagues were failing their tests. Her teacher said she would make a good physics major, and so she did, because her teacher believed she could do it.

Esther married young and had her children while getting her physics degree. After finishing college, she worked for a while and then decided to spend more time with her children. At this time she home schooled them for six years. Then she decided they were grown; now, she wanted to be a college professor. A college professor would need a Ph.D. degree, so she returned to school. Graduate school was a great experience for Esther, except for the hard work. She has no negative remembrances of graduate school. She had great support from her family and particularly from her husband, who would sleep on the sofa of the lab to keep her company. Now Esther is mostly concerned with physics education research, and mentoring students of color, supporting them, and making sure they know they can be whatever they want. Currently, Esther works as an Assistant Professor in the physics department of an HBCU. She is the only Black woman in that department.

Jane.- Jane holds a bachelor's degree in physics and a $\mathrm{Ph} . D$. in applied physics. Jane grew up in a large urban area in the northeastern United States. She is a first generation daughter of immigrants from the Caribbean, where her parents were teachers. For this reason, Jane's parents would push her education, and her mother would go to the PTA meetings. They wanted Jane to be a medical doctor. She was the only daughter and had five brothers.

Jane did not grow up thinking about being a scientist; however, she remembers having a Black male as a science teacher in junior high school. She was also impressed when she had a young female physics teacher who seemed fragile in Jane's eyes, but was "tough" in her urban high school. These two teachers affected Jane for their unusualness. Jane did not have any relatives or friends of the family with a science background, but she liked mathematics. In fact, she was on her school's mathematics team. One of her mathematics teachers told her about college. He suggested she attend a minority student weekend a women's college was promoting. Jane eventually completed her undergraduate studies at that college. Her parents were supportive of her academic choice for the bachelor's degree, even though her father did not understand very well what she was doing. When graduate school came, they did not understand why it took so long, and kept asking her when she would get a job. Their expectations were for her to be a medical doctor, or a lawyer, or maybe a teacher, but the type of career she was pursuing was not familiar to them. She first intended to major in mathematics, but her institution only had pure mathematics, and she liked applied math; she even tried economics, but she did not like that either. One of her professors, however, offered her a summer research 
opportunity to work in another professor's physics lab, and Jane fell in love with physics research.

Jane did not want to do a Ph.D. in physics. She left academia and worked as a research assistant in the health field for a year, until she decided to go back to school and obtain a Ph.D. This program took her eight years, three qualifying exams, and some isolation in the beginning, for being the only Black female in physics at her institution. She concluded her program, and during her academic trajectory, she always had a good relationship with professors and advisors. She remains in contact with some of her professors and major advisor, and even works with others. Currently, Jane is a Research Associate in a large public research university. She is responsible for managing the laboratory, training graduate students, and conducting research.

Shanna.-Shanna holds a bachelor's degree in physics, as well as a master's degree and Ph.D. degree in the same field. She is the only child of a single mother; she grew up in the house with her grandmother and her youngest aunt. From an urban area in the northeastern U.S., Shanna lived in public housing projects her entire life until she went to college. Her mother worked for the school district and was very supportive of Shanna's education.

Shanna attributes part of her personal trajectory to the influence of her almost ten years older "very smart" aunt. Shanna's aunt seems to have opened paths for her. They both went to the same elementary school. Her aunt won an important mathematics competition at the school. Because of her aunt's achievements, the school's principal wanted the aunt to go to the best junior high school in the city but he was never able to get Shanna's aunt to that school. Shanna attributed her aunt's nonadmission to racism in that time. However, when it was Shanna's turn, the principal was successfully able to advocate for her. In junior high, she was part of a science club, and she enjoyed it. She also liked to play with Legos, but her family did not allow her to do so- "No, those are for boys. You have to have pink things, things that are for girls," she was told.

Also during junior high and high school, Shanna was in a summer program to increase the participation of minorities in engineering. Every summer she would go to a different college campus and take preparatory classes for the fall classes. She performed well in mathematics and with most of her friends also being part of these summer programs, the choice for a science field as a major in college came almost naturally. She picked physics because of the college package she received from the university. Shanna attended an HBCU and had research opportunities every summer. For her to continue to graduate school, it was not a choice. It was the necessary path of the physicist's career. Her graduate school experience, however, was not such a breeze, and Shanna found herself isolated and with no support at the PWI. She failed her qualification exams and had to change institutions. It turned out that her advisor gave her an excellent recommendation, and she went to a top institution to work with a prestigious science group. Shanna's relationship with her advisor there was very traumatic, and her experience with academia overall was very painful. She decided she did not want to build a career in academia. Nevertheless, she is very successful in her field, working for a governmental agency and continuously working in outreach activities to support other underrepresented groups in science. Shanna works for a governmental agency in the U.S., where she analyzes electrical engineering projects and products.

\section{B. Emergent themes}

The life stories of these six women scientists are dissimilar in many ways. However, they have some experiences in common. The analyses of the physicists' stories lead to three emergent themes that are discussed in this study: invitation to engage in science, communities of science practices, and isolation in the academy. Following, we discuss these themes along with the obstacles and strategies the Black women physicists share in their stories.

\section{Invitation to engage in science}

One of the themes that emerged as a common experience amongst the women in this study relates to how they started their participation in formal science programs. Their experiences followed a pattern that started with attending science related afterschool programs, college co-optation by physics departments, and engagement in summer research programs during college. Most of the physicists (five out of six) attended after-school or summer school programs related to science, where they were exposed to a science environment at an early age. For example, Shanna was part of a science club in junior high. She said, "That's one of the things that I remember about like really being into science, being in that Science Club." Still in junior high, and later in high school, Shanna participated in a program targeted to introduce minorities to engineering. In this program, she would attend different college campuses and take preparatory classes for the fall school classes. "And so I was surrounded by a bunch of kids who were interested in math and science and engineering, at least outside of regular school," Shanna pointed out. These programs also exposed the students to science research. Allyson talked about her first physics research experience happening in high school. She said,

When I was in high school, I did a lot of summer programs that were in math and science. And I would say junior year of high school, I went to the [university], and I did a physics program. And there were tons of experiments that we did, and that was like my first research experience, even though I was a high school student. (Allyson) 
Betty felt like she was co-opted by mathematics competition programs as a path to science through mathematics and testing. She described her initial engagement:

So one of the things that happen when you show early promise in these areas, at least at that time, and I was in public schools, is you quickly get sucked into-it used to be called Math Counts searches. They were basically sophisticated standardized tests, and they were looking for people who were prodigies and had special talent in certain areas, and so they would do everything from testings that were far above what you could have known at that age, and just test for things that you were curious about. The best thing I ever got out of them was just I became fearless with regard to testing because I did so much of it. (Betty)

Betty also did a summer program at a national laboratory engaging in science research.

Similarly, Christa had experiences in national laboratories. She spent two summers working at NASA when she was still in high school. Jane was part of a math team in high school as well. After these experiences in afterschool and special programs, the physicists said they were already in the mindset of choosing a major in science when they chose to go to college: First, because they had already experienced it, and, second, because their friends were also part of these science communities. As Shanna illustrates, it was not much a matter of what major to choose but one that was decided for her because of precollege program participation and picking one of the STEM areas: "And so we all were brainwashed into thinking, 'You must major in engineering or science.' It's not a matter of 'if'-it's just picking which one," she says.

In addition to the community building sentiment, these programs also helped to inform the students about sciencerelated professions. Betty's comment exemplifies both of these aspects:

There's a way in which if you achieve at a certain level, you know, you sort of end up in the same kind of places. You do the same kind of programs. You get recruited by the engineering schools a lot, especially these kind of programs that are looking to increase students of color in these disciplines. And you know, I guess I knew what an engineer was because I had been in lots of programs. (Betty)

All the physicists chose their majors for at least one of the two following reasons: more intense exposure to practices in physics in comparison with other fields of science, and/or more attractive financial packages to major in the field in comparison to other areas. For example, financial reasons weighted more for both Betty and Jane. Jane, for instance, compared the packages from different programs and even though she preferred engineering, the physics financial support was better:
I really wanted to go into engineering. And I thought, but you know, their package was more loans than grants. And [her college] was more grants. That's the only way this is possible, financial assistance, you know? Financial assistance is just a dream, right? (laughs) Who could afford, except for people who come from a wealthy family, you know? Who can afford this kind of education? (Jane)

Although financial reasons helped Shanna's choice also, she adds that she wanted to be different from her friends by majoring in physics:

I did not want to be an engineer because "everybody" wanted to be an engineer and I had to be different. So I was like, okay, I picked physics for two reasons. One, it's different. ... And I got a full scholarship to college predicated on me majoring in physics, because everybody's majoring in engineering, so if you're applying for scholarships, now you have ten thousand people applying for engineering scholarships. Nobody's applying for the physics scholarship (laughs). If you're crazy enough to want to go into physics, they will throw money at you. (Shanna)

Allyson's experience mirrors Shanna's sentiment that there are more funds if one decides to major in physics. Allyson says she went to her university "on a full scholarship, which was truly a blessing because [she] went as a physics major, but it was an NSF-sponsored program. $\ldots$ and you had to either go into physics, chemistry or mathematics, and that was it." She was on a track to major in engineering, since she was participating in a program to attract minorities into engineering, but she went to physics for the scholarship that was attached to majoring in specific science related fields, and physics was the closest path or the "foundation for engineering," as she put it. The NSFfunded program that Allyson mentions aimed to increase significantly the number of students in STEM fields in HBCU's. From the six physicists in this study, four attended historically Black colleges and universities.

\section{Communities of science practices: Science research programs}

Similar to the invitation to engage in science, which greatly influenced the choice of major for the physicists, there is a moment in their trajectories in which the women physicists engage in summer research programs along with their academic training. We identify these programs to resemble what Lave and Wenger [36] call "communities of practice." This refers to a group of people who share concern or passion for something they do, and they learn through regular interaction with each other on how to improve their practices. A community of practice involves three basic components: the people that are interacting, the domain of interest they have in common, and the practices 
in which they engage together. In these summer research programs, the physics students would go to different universities, research institutes, or national laboratories and work during the summer, interacting with scientists and engaging in genuine science research. These spaces, therefore, are seen as communities of science practices and seem to positively affect the participants' career choices.

All the physicists in this study reported attending summer research programs during their undergraduate education. These experiences influenced the career choices they made later on, either for helping them to choose a field of physics they found interesting, learning about post-doctoral opportunities, or deciding the type of institution where they wanted to work. In those programs, the women were introduced to the culture of physics from participating and becoming protagonists of the physics research community. Beyond content knowledge, those spaces provided a deeper exposure on the culture of physics for these women.

Some summer research experiences aim to offer training with perspective on job placement after the students' graduation. That was Esther's experience. She worked at NASA during the summers as an undergraduate student where "the purpose, of course, was that they would offer me a job upon my completion," but she realized that type of work environment was not in her future. She said, "Over the time of going, I think I went three times [to positions at NASA], two summers and one semester. I just did not like the environment, so I didn't take that job."

In addition to the work environment, the scientists learned about different fields of physics that they might enjoy. For example, Jane talks about her summer experiences as a place to try research in fields different from those in her department:

I went to [research lab]. I didn't like that program, but it was interesting. Actually, all of them made me realize, it's funny because I went to explore other areas within physics. I was like, okay, I did this, and laser stuff, let me see what else. So part, I realized I didn't want to do particle physics, cosmology, not that, and then the other one I worked at (pause) I worked at [an institute]. They hire, but they do mostly modeling and I realized I didn't want to do that. (Jane)

Jane brought up another important aspect of summer research programs - these were funded opportunities. Jane said, "The summer research program. I got paid for that, yeah ...Yeah, and that continued, and that made like every summer." In a way, these programs constituted a financial aid for the students during summer to support their education during the academic year.

Overall, most of the physicists enjoyed their summer research programs. Christa, for example, stated, "All of my summer research experiences were wonderful. I've learned a lot and still use some of the things, the knowledge that I gained during those experiences."

\section{Isolation in the academy: The study groups}

The last emergent theme in this study relates to the isolation experienced by the women physicists in their graduate programs, particularly in the study groups. During graduate school, the site of isolation was the study groups. The physicists talked about feeling isolated from their colleagues in the physics department and having difficulties entering the study groups. While some fields rely heavily on reading and writing, STEM requires students to work on mathematical exercises and problem solving. Students in these fields dedicate a considerable amount of their study time solving exercises and problems repeatedly. The support of study groups for this activity is extremely important because students not only can share the final response of the problems, and check if they are on the right track, but also discuss how to solve the problems. Besides, there is a tradition for students to share their material with students of another semester, where there is a social network of problem solving. Shanna explained, "You know, like the Chinese kids have solutions to the textbook written in Chinese."

The physicists talked about how hard it was to integrate the study groups and how they were excluded from participating in them. Jane shared, "People would notor they'll tell me, oh, they're not studying and find out they're studying together, so I was studying on my own and having a hard time. So yes, I was excluded; especially in graduate school, I was excluded." (Jane).

Because she failed her qualifying exams at her first university, Shanna had graduate school experience from two institutions. In the first institution, she would have to come out of her comfort zone. She said, "You want to have a study group with people who you feel like you, have something in common with, and until you actually get to know someone, all you have to go on is what you see," and all that she saw was "very tall" Russian students. "[T]here were a lot of Russians in our department. They would all study together, and they would all speak in Russian, and they all knew [each other], you know, went to the same schools and stuff," Shanna contextualized. This network was hard to penetrate. In the second institution, Shanna realized she had to be more proactive in order to join the study groups:

But when I started at [second university], I already knew. All right, I gotta break into these study groups. I have to make friends. I have to go to the Happy Hours. I have to go too. I have to do these social activities because it builds these bonds. So I was quite a social butterfly when I was at [second institution]. I was department representative. I was in lots of groups and organizations and all that stuff. And it helped me to be more included, but even now, I still feel excluded. [...] Like so if we're at cookies and tea and they're talking about a study group, I'm like, 'Oh, you guys are 
studying Tuesday at two? I'm going to come.' See, I didn't have to ask, 'Will you invite me?' I'm not going to wait for that. I'm going to come. I'm going to show up. (Shanna)

Therefore, the strategy of self-invite seemed to work for Shanna. Once in the group, Shanna became a contributing member: "It helped that I had a master's from [first institution] when I got to [second institution] because then it's like, well, maybe she does know something and can be of benefit."

Moreover, Jane talked about how exclusion from the study groups affected her confidence:

It was very hard for me because I was struggling and I was feeling I was stupid. I couldn't get it, and they're getting it and [I'm] not understanding how they're getting it. Or they're getting it because they had access to previous tests, homework solutions, you know, from previous years from previous students (Jane).

Jane said she learned the other students had all these resources only a year later, and then she realized, "It's not that they're smarter than [her], but they had the resources," and she was by herself, "sitting there trying to figure out on her own."

Allyson talked about how she felt with her transition from a "nurturing and supportive" environment at her HBCU to an "extremely competitive" PWI. Similarly to Jane, Allyson observed that her colleagues had resources she did not have. She said people tried to exclude her from science, for example, by "having lab mates withholding information, and resources from experiments and classes that [she] needed." Unlike Shanna, who tried to integrate with the other students, both Jane and Allyson used a strategy of forming a group of their own. Jane formed a study group with other minority students from different disciplines across the university:

And that's when I was so happy when these students came along because even though, I mean, the only thing that united us, we were black, but we were struggling. We all felt that, so we all had to like work together. Or not even that, also there was this Hispanic student from [Latin America]. Because we were isolated, we were two in the lab so we worked together because we only had each other to work together. We didn't have anybody else (Jane).

Jane talked about how she gathered with international students from Latin America and Africa because her White peers would exclude her. She also talked about the relationship with the few other women in the program:

[...] interestingly in this program, I didn't have any females. There was the one female that came, she left for a master's, or you may have Asian females, Chinese females, but they tend to stay in their own, you know, own group. But in terms of us and the American students, you know, I wasn't part of their club, you know. As much as I tried, I just couldn't. I couldn't get information out, so in terms of you know, so really like [the Latino American student] and the two African students, we ended up being, we kind of built our own support group to make it through the program (Jane).

Allyson summed up saying that "in order to be successful in graduate school" it was necessary to develop a network, an "academic posse." She had a support network formed by students of color that were also recipients of her scholarship. When she felt she needed their help, Allyson would look for them: "I'm going to be smart about this. I'm going to call my support group. I'm going to call on my academic posse, and I called them" (Allyson). They have a nickname, "The Black Mafia," she said. They were in different programs, but faced some similar situations in graduate school, and they supported each other.

\section{DISCUSSION}

This discussion of the findings focuses on addressing the obstacles the six Black women physicists face during their trajectories, and the strategies they use to overcome these obstacles. We discuss implications of this work and offer recommendations in support of Black women and students of color in general pursuing physics, STEM, and science related fields.

\section{A. Facing obstacles: The persistence of racism}

One tenet of critical race theory speaks about the persistence of racism in the United States, not the open and extreme cases of racism, such as prohibiting a person of color from sitting anywhere in a restaurant, but the type of racism that is pervasive, constant, and part of our ordinary lives. For the first cases, affirmative action policies help remedy the situation. The latter, however, is sometimes harder to identify and address. The counterstories of the Black women scientists in this study provide some insights on structural and everyday racism in the trajectory of becoming a physicist.

It is common to find in the literature reasons why students of color fail [26,37] and how underrepresented they are in Advanced Placement (AP) classes or STEM disciplines [2]. Some of these reasons are noted in the counterstories of the women in this study (i.e., Allyson, Betty, Christa, Esther, Jane, and Shanna). Research also points out that lack of parental support and school involvement are predictors for students' failure in school. Brewster and Bowen [38] found that the importance of teachers in affecting students' school engagement is greater than parents' engagement, and yet the scientists' counterstories present teachers that dismiss their attempts to 
engage in science, in spite of strong family support (e.g., Allyson, Christa). This shared sentiment of teachers' lack of support and uneasy feeling in AP classes is coherent with research results noting how teachers express lower expectations for minority ethnic students [39]. In addition, within a CRT framework, these situations constitute microaggressions [40] in school. Racial microaggressions are everyday interactions that send harmful messages to people of color; they are subtle, constant, and insidious racist attacks [41]. Experiences of surprised looks from colleagues and teachers, differential treatment, and being outnumbered in a classroom send to young women of color the message they are out of place. Adding to this is an absence of representation of Black women scientists in the media, textbooks, and lesson plans. Collectively, these microaggressions create an environment that teaches young Black girls that they do not belong in science and are not welcomed to pursue careers in STEM.

This study unveils obstacles Black women face in science once they select to major in STEM. It is a mechanism of exclusion through the study groups' phenomenon. Study groups represent more than a site of peer support but an essential part of the learning process in STEM. To be part of these study groups means to enter a network that promotes the sharing of solved exercises and problem lists among students. Members of these groups are mostly White or Asian men and Asian women. The Black women physicists in this study find it difficult to enter these networks and therefore have limited access to resources that contribute to their academic performances. Consequently, they feel isolated in their departments and experience a decrease in their self-efficacy [42], which is one of the factors for success of minorities in STEM. The decrease of self-efficacy happens when the women scientists feel other students are learning the material, solving the problem lists, and doing better on the exams while they are struggling with the same materials. Because they are not part of the study groups, they do not realize the other students have more studying aids (e.g., answers to problem lists), and therefore are at an advantage.

The ethnic and racial composition of the study groups seem to be more salient than gender positionality. The Black women say being a woman is more of an issue than being Black in their physics departments. When it comes to integrating study groups, the women talk about the other students being White Americans, Asian, or White Europeans more than the fact they are predominantly men. Recall Shanna speaks of the few other women in her program who are Asian, yet they do not socialize with her either. The White and Asian students, both male and female, seem to have automatic membership into the study groups. They form an exclusive club who represent "honorary Whites" [43] (p. 179), for they are not underrepresented in STEM and benefit from the same privileges of White students [44]. When White and Asian students get together and share answers from problem lists, and the Black women are left behind, not invited, or not informed of study groups' meeting times, the permanence of racism is clear. When this situation is repeated regularly, it constitutes instances of microaggression [45].

In addition, these Black women scientists are usually one of the few women in their departments, making it harder to socialize with other women. The presence of other Black students in the science departments of these women is small or nonexistent, and socialization for these women with other students that share their racial background is not possible. This environment, combined with the exclusion from the study groups, makes Black women physicists feel isolated. The intersection of race and gender hinders the social integration of Black women physicists in graduate school and exposes the racism amongst students in STEM departments. There are no possibilities to shift the racialized gender experiences in this instance to solely gender experiences. The study group phenomenon makes explicit the intricate nature of race and gender in science. The exclusion of invitation and participation of the study groups to Black women in STEM departments are detrimental to the learning process and to the self-efficacy of these women. Consequently, their academic achievement is compromised. Social integration is a factor associated with academic achievement [46], and this is even more important for the study groups' dynamics in STEM fields. The dominant narrative places academic achievement in relation to factors such as parental education, family income, and student's perseverance, and downplays the role of the racial social climate in STEM fields. The counterstories, however, unveil how racism can interfere in the students' learning and performance in physics. Next, we discuss how the scientists participating in this study overcome the obstacles they face.

\section{B. Overcoming obstacles: Interest convergence}

\section{Federally funded programs}

Another tenet of critical race theory is the principle of interest convergence that states, "the interest of [B]lacks in achieving racial equality will be accommodated only when that interest converges with the interests of whites in policymaking positions" [47] (p. 69). We understand the presence of a Black woman in a physics department as a case of interest convergence because of the underrepresentation of women and Black people in STEM fields and the country's need to produce more scientists. While racism teaches young women of color they do not belong in Advanced Placement courses and push them away from science, policymakers need to increase diversity in academia and create equity programs to invite and welcome them in.

This study focuses on stories of success; therefore, we cannot talk about what happens to those who started the process of becoming a physicist but did not finish it. 
However, the life experiences of successful women of color gathered in this study show that federal funding is a common factor in their trajectories, leading to successful careers in science. Federal agencies such as the National Science Foundation (NSF) and the National Aeronautics and Space Administration (NASA) seem to serve as invaluable resources. These institutions and the programming they fund start and support the academic and professional trajectory of the scientists in this study at an early age. Funding from NSF throughout their education-from the earlier stages of their training, during college, or graduate school-is vital to the six women in their careers as scientists. The funding opportunities from NSF specifically target underrepresented groups in science, and support grants to scientists already established in their careers as advisors. Similarly, NASA scholarships and funding initiatives specifically for underrepresented groups supports the women as well. Five out of six participants in this study were funded by NASA at some point, with programs ranging from high school to college, and funding ranging from four months to three years (such as their participation in three consecutive summer programs). The funding is directly related to equal opportunity programs and actions that address structural racism present in this society. Their stories of success from receiving the benefits of federally funded programs targeted to underrepresented groups in science are critical in their successful careers. These are necessary programs and similar actions should be implemented by schools and universities, independently of governmental support. Though beneficial, they are not sufficient.

To make another connection, studies show numerous factors that influence students' choice of an academic major [48-50], mostly drawing results from test score data, socioeconomic status (SES), parents' education, and high school course enrollment. Some studies report self-efficacy as an important factor for enrollment in STEM fields [51], but little has been said about the role university recruitment initiatives play on making a decision about a college major, particularly for students who go into STEM fields after participating in federally or otherwise supported science programs. Because fewer candidates want to study physics in comparison, for example, to engineering, the financial aid incentives tend to be more generous for the women who selected physics as a major. Therefore, funding is an aspect that we cannot leave out of the equation when analyzing the presence of underrepresented groups in STEM degrees. It is a reality that people of color are more likely to face financial hardships when applying to and persisting in college, and a deterrent for few Black students' success in STEM [13]. Science can be interesting, engaging, and passionate, but many families and individuals of color also yearn for financial security. Sustaining and guaranteeing funding for precollege programs or research experiences during college can be the deciding factor in increasing the number of underrepresented groups in STEM fields, or keeping us away.

\section{Strategies for inclusion}

In regards to the study groups, the feelings of isolation and alienation of minority students in PWI institutions can be associated with uncomfortable feelings with the social environment [46]. The physicists in this study use two approaches to resolve this situation. The first approach is to force themselves into the study groups, or they "show up" and join the groups without an invitation, such as the case of Shanna by finding out when her colleagues are meeting and self-inviting herself to the groups. To deal with the isolation overall, the physicists join events that happen in the STEM departments such as happy hour or cookie-and-tea time, not solely out of desire, but of necessity to be seen and accepted as part of the group. They have to reach out to other students, try to connect, and show the other students how the group can benefit from their presence and knowledge in the study groups. For example, Shanna uses her previous master's degree from a prestigious institution to leverage her entrance into a study group. Keeping with a critical race theory framework, we identity this behavior as interest convergence [24] in the study group phenomenon. Shanna's access and then acceptance into the group is only possible because it is beneficial for her as well as a gain for her peers.

The second approach is to find racial minority students from other programs and form a support group. Saenz et al. [46] say that some minority students in PWI's "choose to associate primarily with students from a similar ethnic or racial background to provide security and racial identity" (p. 200). However, this "choice" seems not to be a choice at all. After trying to socialize with White and Asian students and failing, the Black women decide to pool their available human and academic resources in the formation of their own racial, ethnic, and gender support. This support network of other ethnic minorities is outside their STEM program. These other minority students are likely forced to seek external support as well outside of their programs, and the welcomed space of other "outsiders" become a close community of support during their education. It is plausible that their first choice is to socialize with other Black students within their department as a "comfort zone", but these women are still the only Black students in their STEM departments, and it becomes more of a necessary act to seek support among other Black students in other departments and programs, who likely are in need of support too.

\section{Implications and recommendations}

The findings of this study present implications for the physics education community and physics community as a whole. From a classroom perspective, teachers and teacher educators can make use of storytelling to unveil and validate the experiences of students of color in science [30]. Similarly, physics educator researchers can use this tradition as a methodological tool to expand the community's knowledge on the experiences of people of color in STEM fields. It is not enough to think about the education of physicists only within 
the physics education community because, ultimately, physicists are trained and enculturated by other physicists that may or may not have educational concerns or a mentoring mentality in regards to students of color. Therefore, it is important to educate physicists overall. Specifically, physicists need to be aware that current practices in the laboratory and in physics departments might affect people of color differently by failing to provide an inclusive and fertile environment for researchers of color. Even professional organizations for students and early career faculty of color can provide a community of support among emergent scholars of color [52]. Accordingly, physics departments and physicists should provide students of color access to and awareness of professional associations such as the National Association of Black Physicists, the National Society of Hispanic Physicists, and the Committee on the Status of Women in Physics (of the American Physical Society). Likewise, they should encourage students to join these associations and present their physics research at the conferences of these organizations. By doing so, the physics community validates the physics production of women of color, and students of color in general.

From the counterstories of the women in this study, Black women experience unique challenges of socialization in STEM, and physics departments should provide a more inclusive and supportive environment for them. With this, physics departments may serve Black women and students of color more by promoting study group participation among all students. Putting students into contact with each other, making study and practice problems open to all may limit the feeling of exclusion to certain knowledge that some students have and others do not. We feel that students within science departments become aware of their unconscious and conscious prejudices through seminars that unintentionally target students of color, yet promote collaborative and supportive science learning environments for all students.

Finally, we find the summer research programs during college to be particularly successful in supporting and nurturing the Black women in this study. The ways in which these programs are structured and how these experiences for women of color help to shape their identity are worthy of study. We believe it is unlikely that these are truly neutral spaces in regards to practices of exclusion for people of color, given that these science research programs are a microcosm of scientific training; yet, our expectation is that they would mimic what happens in science institutions at large and could shed valuable light on how these spaces support women and students of color in developing interest and identity in physics, no less STEM fields.

\section{CONCLUSION}

Overall, the data suggest that afterschool programs that focus on academic performances or scientific practices, college recruitment, and funding are fundamental for Black women to choose physics over other STEM fields. When focusing on academic performance, these programs create communities of science practices, an environment that privileges hard, steady work, problem solving, and excellence on tests and exams. The programs that focus on science practices provide an environment that promotes science skills, collaborative work, and experimental scientific processes. By the time the scientists-in-the-making decide to go to college, they decide to apply for a physics major because they know they perform well and because they receive a good financial package. The six Black women participants in this study may not particularly have liked physics at first, meaning in middle school and high school, but all of them liked mathematics and performed well in that subject in school. They grew to love physics as their education continued. Obtaining a degree in physics is still a challenge, yet an attainable goal as they are familiar with the strict problem-solving content aspect of the degree. Self-efficacy, then, plays an important role for the choice of major.

In addition, the institutions that promote recruitment specifically targeting underrepresented groups in STEM fields offer attractive financial aid for these women. Thus, high self-efficacy, prior exposure, and financial support become critical elements in these women having careers in physics. In our analysis, the financial support weighs significantly. This is not to say that money is the ultimate factor in these women's decision making, since their academic precollege experiences play an important role. Nonetheless, the stories of the women clearly point to financial aid as a strong contribution to set these Black women on the course for physics as a college major and a scientific identity. Once they are on track, they discuss with much excitement, love, pleasure, and passion physics content, and refer to specific events in their laboratory or their research. They develop a strong affective connection to physics - the content of physics, its practices, and application, which is undeniable. It is their passion for physics that helps them to persist and to pursue additional opportunities in physics.

We hope to contribute to conversations on gender, race, and ethnicity in science education, particularly in the physics education community. Gender and race relations affect the learning and development of science. As a community, we can learn from these experiences and foster the presence of underrepresented groups in STEM.

\section{ACKNOWLEDGMENTS}

This material is based on work supported by the Brazilian government through CAPES, the Fulbright Program, Comissão Fulbright Brasil, and the Office of Diversity at Teachers College, Columbia University. 
[1] A. Hurtado, in Knowledge, Difference, and Power: Essays Inspired By Women's Ways of Knowing, edited by $\mathrm{N}$. Goldberger, J. Tarule, B. Clinchy, and M. Belenky (Basic Books, New York, 1996), pp. 372-392.

[2] L. Perna, V. Lundy-Wagner, N. D. Drezner, M. Gasman, S. Yoon, E. Bose, and S. Gary, The contribution of HBCUs to the preparation of African American women for STEM careers: A case study, Res. High. Educ. 50, 1 (2009).

[3] M. Ong, Body projects of young women of color in physics: Intersections of gender, race, and science, Soc. Probl. 52, 593 (2005).

[4] L. T. Ko, R. R. Kachchaf, and M. Ong, Agency of women of color in physics and astronomy: Strategies for persistence and success, J. Women Minorities Sci. Eng. 20, 171 (2014).

[5] The principal investigator in this study is a black woman physics educator who was raised in Brazil. She went to the United States as an international scholar to work with and conduct research about black women in science. The second author is an African American woman who majored in biology in college and worked for a short time in industry and in the medical field. She was raised in the southern United States and taught high school science. One of the goals of this larger project is to provide information about successful experiences carried out in the U.S. that foster access and participation of underrepresented groups in STEM and see how these experiences can be applied to other countries.

[6] U. S. Census Bureau, 2004 American Community Survey, available at https://www.census.gov/population/www/ censusdata/ACS_reports.html (2010).

[7] The terms black people, and people of African descent will be used interchangeably along this text. The terms African American, and people of color will be used in quotations when the original authors have adopted the term. All the six participants in this study identified themselves as black or African American. The first author (Rosa) is black Latin American; the second author (Mensah) is African American. We reserve the term American for all the peoples of the Americas. Also read Maulucci Rivera, and Mensah (2015) for explanation of terms. M. S. Maulucci Rivera and F. M. Mensah, Naming ourselves and others, J. Res. Sci. Teach. 52, 1 (2015).

[8] L. C. Landivar, Disparities in STEM employment by sex, race, and Hispanic origin, American community survey reports (U.S. Census Bureau, 2013). Available at http:// www.census.gov/prod/2013pubs/acs-24.pdf.

[9] National Science Foundation, National Center for Science and Engineering Statistics Report NSF 13-304, 2013. Available at http://www.nsf.gov/statistics/wmpd/2013/.

[10] A. Johnson, Unintended consequences: How science professors discourage women of color, Sci. Educ. 91, 805 (2007).

[11] B. Love, Issues and problems in the retention of Black students in predominantly white institutions of higher education, Equity and Excellence Educ. 26, 27 (1993).

[12] E. Seymour and N. Hewitt, Talking about Leaving: Why Undergraduates Leave the Sciences (Westview Press, Boulder, CO, 1997).

[13] C. Steele, A threat in the air: How stereotypes shape intellectual identity and performance, Am. Psychol. 52, 613 (1997).
[14] K. Maton, F. Hrabowski, and C. Schmitt, African American college students excelling in the sciences: College and postcollege outcomes in the Meyerhoff Scholars Program, J. Res. Sci. Teach. 37, 629 (2000).

[15] J. Moore, in Retaining African Americans in Higher Education: Challenging Paradigms for Retaining Students, Faculty, \& Administrators, edited by L. Jones (Stylus Publishers, Sterling, VA, 2001), pp. 77-90.

[16] E. Walker, Cultivating mathematics identities in and out of school and in between, J. Urban Math. Educ. 5, 66 (2012).

[17] S. W. Brown, Hispanic students majoring in science or engineering: What happened in their educational journeys?, J. Women and Minorities Sci. Eng. 8, 123 (2002).

[18] H. Carlone and A. Johnson, Understanding the science experiences of successful women of color: Science identity as an analytic lens, J. Res. Sci. Teach. 44, 1187 (2007).

[19] M. Russell and M. Atwater, Traveling the road to success: A discourse on persistence throughout the science pipeline with African American students at a predominantly white institution, J. Res. Sci. Teach. 42, 691 (2005).

[20] K. Crenshaw, N. Gotanda, G. Peller, and K. Thomas, Critical Race Theory: The Key Writings that Formed the Movement (New York Press, New York, 1995), pp. xiii-xxxii.

[21] R. Delgado, in Critical Race Theory: The Cutting Edge, edited by R. Delgado (Temple University Press, Philadelphia, 1995), pp. xiii-xvi.

[22] E. R. Carlton Parsons, B. Rhodes, and C. Brown, Unpacking the CRT in negotiating white science, Cult. Stud. Sci. Educ. 6, 951 (2011).

[23] B. D. Tatum, Why are All the Black Kids Sitting Together in the Cafeteria?: And Other Conversations about Race (Basic Books, New York, 2003).

[24] D. G. Solórzano and T. J. Yosso, Critical race methodology: Counter-storytelling as an analytical framework for education research, Qual. Inq. 8, 23 (2002).

[25] D. A. Bell, Jr., The unintended lessons in Brown v. Board of Education, New York Law Sch. Law Rev. 49, 1053 (2005).

[26] G. Ladson-Billings and W. Tate, Toward a critical race theory of education, Teachers Coll. Rec. 97, 47 (1995).

[27] G. Ladson-Billings, Preparing teachers for diverse student populations: A critical race theory perspective, Rev. Res. Educ. 24, 211 (1999).

[28] E. R. Carlton Parsons, in Handbook of Research on Science Education, edited by N. Lederman and S. Abell (Routledge, New York, 2014), pp. 167-186.

[29] M. Butler, in Multicultural Science Education: Preparing Teachers for Equity and Social Justice, edited by $\mathrm{M}$. Atwater, M. Russell, and M. Butler (Springer Netherlands, 2014), pp. 29-39.

[30] F. Mensah and I. Jackson, (Re)visions of science and science teaching: Students of color transforming their ideas of teaching science in urban schools, Proceedings of Critical Race Studies in Education Association Conference, New York, May, 2012 (2012).

[31] We assessed at a case-by-case basis and it turned out all the participants had all their education in the United States. 
[32] This number refers to the most recent update of the database on June 19, 2015. Available at http://www .aawip.com/physicsastro.html.

[33] J. M. Corbin and A. Strauss, Grounded theory research: Procedures, canons, and evaluative criteria, Qual. Sociol. 13, 3 (1990).

[34] S. Spall, Peer debriefing in qualitative research: Emerging operational models, Qual. Inq. 4, 280 (1998).

[35] F. Moore, Positional identity and science teacher professional development, J. Res. Sci. Teach. 45, 684 (2008).

[36] J. Lave and E. Wenger, Communities of Practice: Learning, Meaning, and Identity (Cambridge University Press, New York, 1998).

[37] J. Cummins, Empowering minority students: A framework for intervention, Harv. Educ. Rev. 56, 18 (1986).

[38] A. B. Brewster and G. L. Bowen, Teacher support and the school engagement of Latino middle and high school students at risk of school failure, Child Adolesc. Soc. Work J. 21, 47 (2004).

[39] L. Archer, J. Dewitt, and J. Osborne, Is science for us? Black students' and parents' views of science and science careers, Sci. Educ. 99, 199 (2015).

[40] C. Pierce, J. Carew, D. Pierce-Gonzalez, and D. Wills, An experiment in racism: TV commercials, Educ. Urban Soc. 10, 61 (1977).

[41] N. Rollock, Unspoken rules of engagement: navigating racial microaggressions in the academic terrain, Int. J. Qual. Stud. Educ. 25, 517 (2012).

[42] A. Bandura, Social Foundations of Thought and Action (Prentice-Hall, Englewood Cliffs, NJ, 1986).

[43] E. Bonilla-Silva, Race without Racists: Color-Blind Racism \& Racial Inequality In Contemporary America (Rowman \& Littlefield, Lanham, MD, 2010).
[44] NSF, National Science Foundation, Scientists, and Engineers Statistical Data System, available at http://www.nsf .gov/statistics/wmpd (2006).

[45] D. W. Sue, Microaggressions in Everyday Life: Race, Gender, and Sexual Orientation (John Wiley \& Sons, Hoboken, NJ, 2010).

[46] T. Saenz, G. A. Marcoulides, E. Junn, and R. Young, The relationship between college experience and academic performance among minority students, Int. J. Educ. Manag. 13, 199 (1999).

[47] D. Bell, Silent Covenants: Brown vs Board of Education and the Unfulfilled Hopes for Racial Reform (Oxford University Press, New York, 2004).

[48] R. Ehrenberg, Analyzing the factors that influence persistence rates in STEM field, majors: Introduction to the symposium, Econ. Educ. Rev. 29, 888 (2010).

[49] S. Maple and F. Stage, Influences on the choice of math/ science major by gender and ethnicity, Am. Educ. Res. J. 28, 37 (1991).

[50] J. Simpson, Segregated by subject: Racial differences in the factors influencing academic major between European Americans, Asian Americans, and African, Hispanic, and Native Americans, J. Higher Educ. 72, 63 (2001).

[51] P. Post, M. Stewart, and P. Smith, Self-efficacy, interest, and consideration on math/science and non-math/science occupations among Black freshmen, J. Vocat. Behav. 38, 179 (1991).

[52] M. Rivera Maulucci and F. Mensah, in Moving the Equity Agenda Forward: Equity Research, Practice, And Policy In Science Education, edited by J. A. Bianchini, V. L. Akerson, A. Calabrese Barton, O. Lee, and A. J. Rodriguez (Springer, New York, 2012), pp. 295-316. 